Goldschmidt 2021 Abstract

https://doi.org/10.7185/gold2021.5438

\section{Oxygen and Hydrogen Isotopic Composition of Zag Water Measured by Cavity Ring-down Spectroscopy}

\author{
RYAN C OGLIORE ${ }^{1}$, GERARDO DOMINGUEZ ${ }^{2}$ AND \\ LAUREN TAFLA ${ }^{3}$ \\ ${ }^{1}$ Washington University in St. Louis \\ ${ }^{2}$ California State University, San Marcos
}

${ }^{3}$ UCLA

Presenting Author: rogliore@physics.wustl.edu

Brine inclusions in halite and sylvite crystals found in the Zag and Monahans ordinary chondrites are among the only samples of liquid water from the early Solar System. The parent body of these inclusion-bearing salt crystals is proposed to be Ceres, an asteroid/dwarf planet of spectral type $\mathrm{C}$. A precise measurement of the $\mathrm{H}$ and $\mathrm{O}$ isotopic composition of fluid inclusions will allow for a comparison with water compositions estimated from secondary phases in other asteroid parent bodies (particularly the carbonaceous chondrites which are thought to be derived from Ctype asteroids).

We measured $\delta \mathrm{D}$ and $\Delta^{17} \mathrm{O}$ of water hosted by Zag (H3-6) using novel techniques. We built a custom in-vacuum crushing device that pulverized whole fusion-encrusted Zag stones. Water released during crushing was frozen out in a vacuum line, then reheated to vapor and fed into the input of a Picarro L2120-i cavity ring-down spectroscopy instrument. We crushed the stone then measured the released water vapor multiple times until the released water was below the CRDS detection threshold. Using this technique, we measured $\delta \mathrm{D}$ and $\Delta{ }^{17} \mathrm{O}$ in two Zag stones. We bracketed these measurements with analyses of water standards injected directly into the Picarro's vaporization unit.

Our best measured $\delta \mathrm{D}$ for the two Zag stones was $-151 \pm 8$ and $-126 \pm 4, \Delta \Delta^{17} \mathrm{O}$ was $+7.2 \pm 2$ and $+2.8 \pm 2$ ( $2 \sigma$ uncertainties). We are currently estimating the fractionation associated with transporting water vapor down the vacuum line by crushing water standards in glass tubes inside the rock crusher. We expect this fractionation to be mass-dependent and will not likely affect the measured $\Delta^{17} \mathrm{O}$ values.

Our measurements of Zag water are somewhat higher in $\Delta{ }^{17} \mathrm{O}$ than the inferred composition of water in most carbonaceous chondrites, and consistent with the estimated $\Delta^{17} \mathrm{O}$ in water from ordinary chondrites. The water source of Zag brines may be somewhat distinct from the C-type asteroid water we have indirectly sampled in our meteorite collection. At the conference we will present our estimates of fractionation due to the vacuum line, and an accurate estimate of $\delta \mathrm{D}$ in water from Zag.
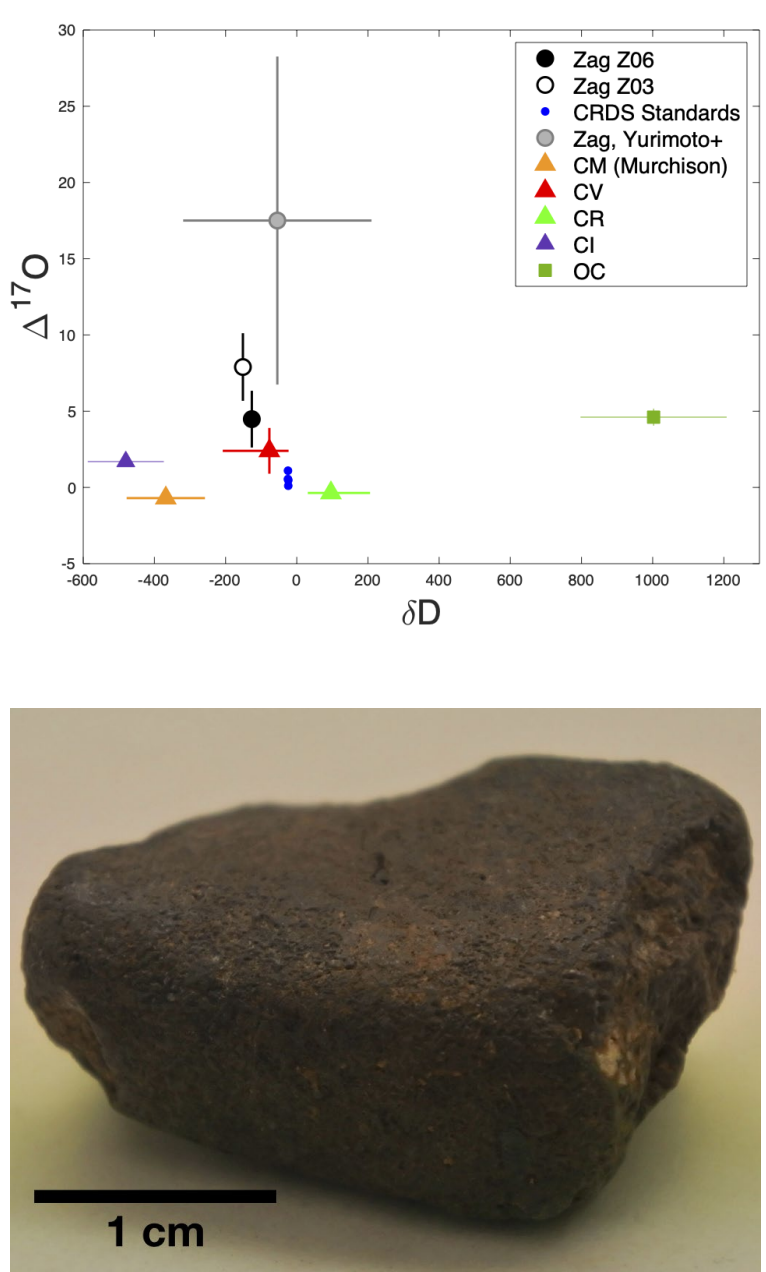